2017-09-01

\title{
Methodological determinism and the free will hypothesis.
}

\author{
rambau, unarine
}

http://hdl.handle.net/10026.1/10070

$10.1037 /$ cns0000135

Psychology of Consciousness: Theory, Research, and Practice American Psychological Association (APA)

All content in PEARL is protected by copyright law. Author manuscripts are made available in accordance with publisher policies. Please cite only the published version using the details provided on the item record or document. In the absence of an open licence (e.g. Creative Commons), permissions for further reuse of content should be sought from the publisher or author. 
Psychology of Consciousness: Theory, Research, and Practice (C) 2017 American Psychological Association 2017, Vol. 4, No. 3, 321-323

http://dx.doi.org/10.1037/cns0000135

This is the manuscript copy of the paper that is published as above

\author{
Methodological Determinism and the Free Will Hypothesis \\ Irving Kirsch \\ Harvard Medical School \\ Michael E. Hyland \\ Plymouth University
}

\begin{abstract}
In this comment on the article by Papanicolaou, we introduce the concept of methodological determinism and discuss the scientific status of the concept of free will. We argue that determinism is an implicit heuristic assumption of modern science, dating back to Newton's Optics. Papanicolaou acknowledges that instance of free will being an illusion have been corroborated. We add that the proposition of free will determining behavior is unfalsifiable. It is, therefore, a metaphysical proposition and not a scientific hypothesis.
\end{abstract}




\section{Methodological Determinism and the Free Will Hypothesis}

Papanicolaou (this issue) maintains that "the illusion of free will remains a mere hypothesis" ( $p$. $x x)$, despite "the incontrovertible fact that under certain conditions the feeling of agency is illusory" (p.xx). I agree that the hypothesis that free will is an illusion that has not been proven. In fact, it cannot be proven. It cannot be proven for the same reason that one cannot prove that all crows are black, that $\mathrm{e}=\mathrm{mc}^{2}$, or that any law of science is true. These are universal propositions, and no amount of confirmatory evidence can prove a universal proposition, because one disconfirmatory future observation (e.g., finding a white crow) would prove it false. This is the classic problem of induction, first identified by Hume, then struggled over by logical positivists when proposing the verification theory of meaning, and later leading to Popper's (2005) idea of falsificationism. Nevertheless, confirmatory tests of hypotheses remain a standard part of empirical science. Thus, "incontrovertible" evidence that the feeling of agency is sometimes illusory (Papanicolaou, this issue) provides support for the hypothesis that free will is an illusion.

But is the proposition that free will is an illusion a "mere" hypothesis? We argue that it is somewhat more than that, because it can be deduced logically from the principle of determinism - the hypothesis that all events in the physical world are determined. Determinism, of course, may not be true. In fact, the Copenhagen interpretation of quantum mechanics argues that it is not. Nevertheless, scientific progress has rested on the implicit assumption that it is, "an assumption that is relinquished only in the face of compelling data" Kirsch \& Lynn, 1997, p. 334) - data such as those that gave birth to quantum mechanics. We shall refer to this strategy of assuming determinism until it is challenged by data as methodological determinism. Note that methodological determinism is not an ontological claim. Instead, it is a meta-theoretical heuristic assumption that guides the formation empirical hypotheses, much like methodological complementarity (Hyland, 1985; Kirsch \& Hyland, 1987) and methodological behaviorism (Watson, 2013). 
Methodological determinism is not a new idea. It is merely a name for a heuristic strategy that has not previously been named. Indeed, the strategy to which it refers was first described by Isaac Newton in the Principia: "The main business of natural philosophy is to argue from phenomena without feigning hypotheses, and to deduce causes from effects, till we come to the very first cause, which certainly is not mechanical" (quoted in Burtt, 1954, p. 287). Note that Newton was not a metaphysical determinist. He believed that God, a non-physical being, affects physical events in the same way that believers in free will believe that a non-physical property of the human mind affects physical events. However, he also believed that the road to finding evidence of God's intervention came from the methodological strategy of searching for non-divine physical causes for all physical phenomena.

The strategy, then, for psychology and neuroscience, is to search for determinants of behavior. This search can be at many levels. It can be at the level of searching for the determinants of significant deliberated choices, such as choosing how to vote or invest one's money, and it can also be at the level of the initiation of particular movements. Free will, if it exits, might operate at both levels, and finding instances in which data can explain these phenomena without recourse to free will are important; indeed, they are the very business of psychology and cognitive neuroscience. Corroboration is important within the philosophy of falsificationism (Popper, 2005). While they do not prove the hypothesis, failures to disconfirm do add to its robustness.

In criticizing the Libet et al. (1983) and subsequent studies, Papanicolaou argues that the choices were in fact constrained, rather than free, because the participants had to "decide and move within a finite and relatively short time interval" (p. xx). However, most (if not all) choices we make are constrained in many different ways. If we wish to deposit a check, go to a restaurant, or shop for groceries, for example, we are constrained to do so during opening hours. If we choose to turn right or left while at an intersection, we generally have to "decide and move within a finite and relatively short time interval." In this sense, behavior is constrained in all experiments conducted in the field of 
psychology. If free choice requires an absence of constraints, as Papanicolaou seems to imply, then the argument against it is easy to make. Papanicolaou even describes some of those constraints. Choices like whom to vote for and whether to buy a particular stock are constrained by "our entire history, that is our character or our personality, our habitual tendencies, our possible addictions and convictions" ( $p$. $\mathrm{xx}$ ). They are also, at least partially, determined by the processes by which judgements are made (e.g., Tversky \& Kahneman, 1981).

Papanicolaou seems to treat free will a hypothesis capable of testing. If that is the case, it is necessary to know how it can be falsified. It is easy to show that some behavior is constrained despite the perception that it is free, and it is easy to show that some behavior occurs without intention. Narziss Ach demonstrated the existence of a determining tendency - i.e., goal oriented behavior carried out without intention - some 100 years ago (Ach, 1910a, 1910b). People perceive they are free, but perceptions and attributions of cause are often known to be wrong. Illusions are not peculiar to the topic of free will.

If the proposition that behavior can be the result of free will - rather than being determined - is a scientific hypothesis, then it must be falsifiable, at least in principle. We contend that it is not. We may someday reach a barrier beyond which further determination is in principle impossible to establish, thereby providing justification for an uncertainty principle in psychology. If so, we will have delimited the domain in which free will might operate. Yet we still will not have established that free will exists. After all, Heisenberg's uncertainty principle does not imply that atomic particles choose their position or momentum. We can think of no data that would establish the operation of free will. The existence of free will is thus a metaphysical proposition, like the existence of god. One may believe in it and still be a good scientist, but the belief is not part of science. 
Ach, N. (1910a). Über den Willen. [On volition] Leipzig: Verlag von Quelle \& Meyer.

Ach, N. (1910b). Über den Willensakt und das Temperament. [On will and temperament] Leipzig: Verlag von Quelle \& Meyer.

Burtt, E. A. (1954). Metaphysical foundations of modern physical science. Garden City, NY: Anchor.

Hyland, M. E. (1985). Do person variables exist in different ways? American Psychologist, 40, 1003-1010.

Kirsch, I., \& Hyland, M. E. (1987). How thoughts affect the body: A metatheoretical framework. Journal of Mind and Behavior, 8(3), 417-434.

Kirsch, I., \& Lynn, S. J. (1997). Hypnotic involuntariness and the automaticity of everyday life. American Journal of Clinical Hypnosis, 40(1), 329-348.

Libet, B., Gleason, C. A., Wright, E. W., \& Pearl, D. K. (1983). Time of conscious intention to act in relation to onset of cerebral activity (readiness-potential). Brain, 106(3), 623-642.

Popper, K. (2005). The logic of scientific discovery. New York: Routledge.

Tversky, A., \& Kahneman, D. (1981). The framing of decisions and the psychology of choice. Science, 211(4481), 453-458. doi: 10.1126/science.7455683

Watson, J. B. (1913). Psychology as the behaviorist views it. Psychological review, 20(2), 158. 